\title{
Job Market Signaling Equilibria with Unobserved Cost Functions and Higher Education Reforms
}

\author{
Giuseppe Rose
}

\begin{abstract}
In this paper we argue that if firms cannot observe the individuals' cost of acquiring education, inefficient pooling equilibria consistent with forward induction may characterize the job market signaling game. Continuous changes in the educational system may affect agents' beliefs generating pooling equilibria consistent with forward reasoning. The welfare comparisons between separating and pooling equilibria should prevent governments to implement too often policies that deeply modify the educational system without a serious long run perspective. The role that European Union' directives may have in addressing long run reforms could be fundamental in order to modernize higher education and to avoid the effects of reforms based on ungrounded political conveniences.
\end{abstract}

\section{INTRODUCTION}

This paper aims at investigating the impact of educational policy reforms on macro equilibria. We argue that an excessive variability of policy measures may lead to inefficient equilibria since, in the presence of incomplete information, education may loose its signal value. This happens since the intensity in the economic policies' implementation can be crucial in determining agents' expectations and beliefs (Lucas, 1976). Using a signaling setting with productive Human capital we show that in the presence of reforms that affect the education quality, equilibria where low and high ability individuals decide to acquire the same level of schooling may arise. We show that these equilibria are consistent with a forward reasoning even if the cost of schooling decreases when ability rises.

The issue is quite relevant in the European Union since in the recent past a number of reforms have been introduced in order to restructure and modernize the higher education sectors in many Member States. In particular we point out that the international debate on higher education reforms cannot ignore that European Union's directives can be an effective device able to avoid the effects of reforms biased by local ungrounded political conveniences. It is well known that in continental Europe universities are characterized by a combination of excessive public control and bad governance coupled with insufficient funding (see Jacobs and van der Ploeg, 2005). A modernization of Europe's universities, involving their interlinked roles of research, education and innovation, has been acknowledged as a core condition for the success of the broader Lisbon Strategy. The main lines that higher education reforms

Manuscript received October 30, 2008. This work was supported in part by the Department of Economics and Statistics, University of Calabria (Italy).

G. Rose is with the School of Economics Mathematics and Statistics, Birkbeck College, Malet Street WC1 7HX London, UK; and with the Department of Economics and Statistics, University of Calabria 87036 Arcavacata di Rende (CS), Italy. (E-mail: g.rose@ems.bbk.ac.uk; giurose@unical.it). should follow have been indicated in the so called Bologna agreement. In this document, having comparable qualifications (Short Cycle, Bachelor, Master, Doctorate) across EU countries has been acknowledge as a necessary starting point. As van der Ploeg and Veugelers (2006) point out, Member States (and not the EU) are primarily responsible for the organization of the higher education reforms. For instance, the Italian higher education sector has been modified, in the light of the Bologna agreement, by introducing Short Cycle and Bachelor instead of the unique five-year course degree. But, at the same time, within this reform it has been also introduced an original (and never experimented elsewhere) system of exchange between a form of "credits" and academic exams. ${ }^{1}$ After both these reforms have been implemented, the new Italian Ministry of Higher Education pointed out the importance of re-reforming the higher educational sector by eliminating this credit exchange system. At the same time, many universities in Italy, in the light of their increased autonomy, are re-introducing for some subjects a unique five-year degree, very similar to that used in the past, eliminating the distinction between Short Cycle and Bachelor degree. Since there is still "a call" for further reforms by the European Commission (2005) and by the Council of European Union (2005) targeted to a sort of "Anglo-Saxonization" of the European higher educational system, it is reasonable to expect new changes in the above quoted Italian system. $^{2}$

In this paper we argue that policies on education should be made carefully and should be mainly characterized by a long run perspective. In particular, we show that the uncertainty induced by an intense use of policy measures may re-establish pooling equilibria in the job market signaling game consistent with forward induction. As it is well known, in dynamic games with incomplete information, it is possible to restrict the number of equilibria that come from the application of the perfect Bayesian equilibrium concept, by using the refinement called intuitive criterion or, more generally, by using a forward reasoning. Typically in these games, there is asymmetric information concerning an agent's characteristic and, at the same time, there are some other elements, on which there is common knowledge, that can be used as a signal to deduce the agent's private information. In the job market signaling game (Spence, 1973) with productive Human capital, where individuals' ability is unobserved by firms, the application of

\footnotetext{
${ }^{1}$ Students may obtain a given number of credits by certified past work experiences and these can be used to reach the 180 credit score which represents a short cycle degree.

${ }^{2}$ Indeed, these changes will occur after the publication of the "Decreto Gelmini" in November 2008.
} 
these refinements leads to the conclusion that, when acquiring education is more costly for low ability than for high ability individuals, only the most efficient separating equilibrium may arise. This conclusion is based on the assumption that there is no uncertainty with respect to the elements that allow obtaining the signal. In particular, it is assumed that firms can always perfectly detect the distance between the costs of acquiring education for a high ability individual and those for a low ability type. However, in a context where Institutions are involved in the signal generating process, this assumption could prove to be too unrealistic. In fact, educational reforms affect the education quality (which in turn determines the individuals' cost functions) and also determine how the cost of schooling changes across individuals with different abilities. We argue that in the job market signaling game, when firms cannot observe exactly the cost of acquiring education, pooling equilibria consistent with forward induction may arise. The presence of uncertainty induced by the intense use of policies that affect the educational system may generate such equilibria. The welfare comparisons between separating and pooling equilibria should prevent governments to implement too often policies that deeply modify the educational system without a serious long run perspective. In fact, as it is well known, a pooling equilibrium is less efficient than a separating equilibrium simply because in the former two inputs with different marginal productivity are paid the same wage, while in the latter wages reflect workers' productivity generating a Pareto efficient allocation of resources. ${ }^{3}$ In this view, we suggest that policies that affect the educational system should be based on indications given by special commissions targeted to identify the main issues and to give informed answers to them. ${ }^{4}$

The paper is divided as follows. Section 2 introduces the Spence model within a framework that will be used to derive the equilibria in the presence of a stochastic process for educational policies. Section 3 describes how the new assumptions are modeled within the Spence model. Section 4 presents the main results and discusses all the possible equilibria that may arise in this framework. Section 5 contains the main indications in terms of policies and Section 6 concludes.

\section{THE LITERATURE}

In order to study the equilibria that may arise in the educational market in the presence of policy variability we use a strategic interaction framework à la Spence where individuals are heterogeneous with respect to their schooling costs because they have different abilities. We explicitly consider productive Human capital i.e., we consider the case where education rises individuals productivity and it also works as a device that makes firms able to formulate beliefs on individuals' ability conditional on their schooling level. Using this framework we

\footnotetext{
${ }^{3}$ For a detailed discussion on welfare properties of pooling and separating equilibria see Mas-Colell, Whinston and Green (1995) or Spence (2002).

${ }^{4}$ France, United Kingdom and United States based, so far, all their main educational policies on reports given by special commissions known as Attali report, Dearing report and Boyer report respectively. For a discussion and indications on complete documents see Rodriguez (2000).
}

can analyze how firms' beliefs and expectations change in the presence of policies that affect the schooling sector.

As it is well known the Spence model (Spence, 1973 and 1974) studies the role of education in signaling individuals' innate ability in a context where the labor force is characterized by high and low ability individuals. From a game theoretical point of view the Spence model is a useful example of dynamic game with incomplete information solved by using the perfect Bayesian equilibrium ( $P B E$ ) concept. Indeed, the application of the $P B E$ concept to the Spence model leads to the identification of an infinite number of equilibria both pooling and separating. This infinite number of equilibria can be drastically reduced only if we impose some restrictions on the agents' beliefs. In particular, only if we consider some refinements of this equilibrium concept, known as intuitive criterion (Cho and Kreps, 1987) or more generally forward induction (Kohlberg and Mertens, 1986), we can restrict the number of equilibria that may arise in the job market signaling game. It is possible to show that, under some conditions, in the Spence model the only $P B E$ that satisfies these refinements is a separating equilibrium.

Consider the following setup where $\theta_{a}$ indicates the worker's ability (with $a=h, l$ and $\theta_{h}=1$ and $\theta_{l}=0$ ), $e$ indicates the education level (with $e \in(0, \infty)$ ) and $w$ represents wage. The workers ability is unobserved by the firms. The share of high ability individuals, indicated by $\gamma$ (with $0<\gamma<1$ ) is common knowledge. The interaction process consists in the following stages. First, each individual conditional on his ability chooses the level of education $e$ he wants to acquire. Secondly, two identical firms observe the education acquired by the individual and they simultaneously make a wage offer $w$ to the worker that will accept the highest of the two wages. The output of a worker in a firm is a linear function $y(e, \theta)$ of his ability and his education with:

$$
y(e, 1)>y(e, 0) \forall e .
$$

Firms maximize profits and the average productivity of a worker is given by:

$$
y^{m}=\gamma y(e, 1)+(1-\gamma) y(e, 0)
$$

The cost of acquiring education, given by both effort and monetary expenditures, is a function $c(e, \theta)$ of both the education level $e$ and the individual's ability $\theta$. Assume that the cost function satisfies the following properties:

$$
c_{e}(\cdot)>0
$$

and

$$
c_{e}(e, 0)>c_{e}(e, 1) .
$$

Considering the following utility function:

$$
U(w, e)=w(e, \theta)-c(e, \theta)
$$




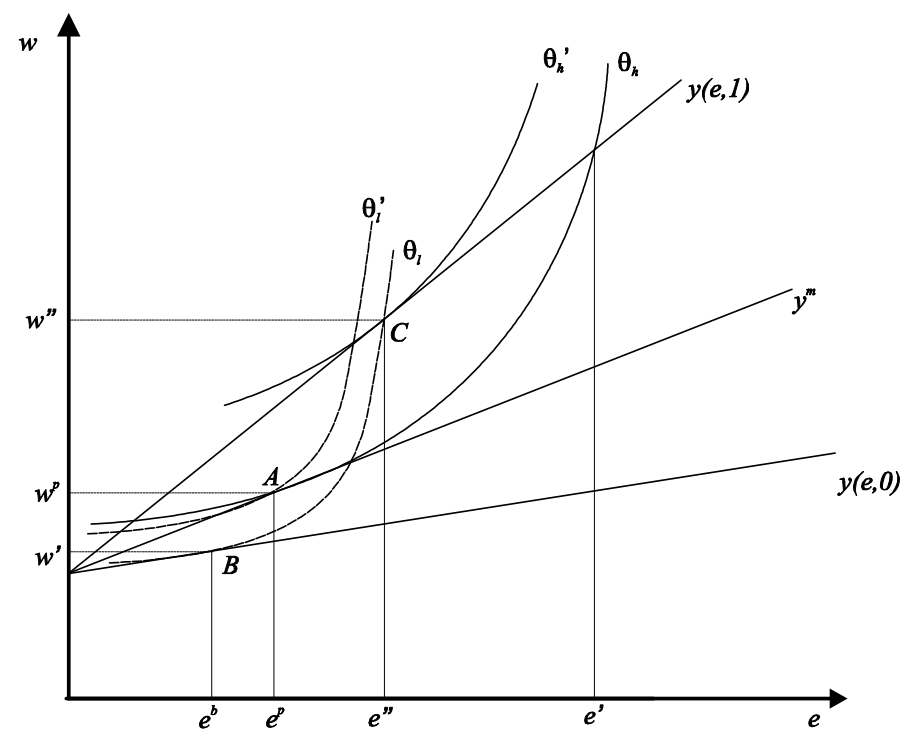

Fig. 1. Pooling and separating equilibria

given assumption (3) it is possible to draw the indifference curves for both the high and the low ability workers $\left(\theta_{h}\right.$ and $\theta_{l}$ respectively) as illustrated in Fig. $1 .^{5}$

Consider Fig. 1 and consider the following assessment $a^{p}=$ $\left[a_{i}, a_{f}, b(e)\right]$ where $a_{i}$ and $a_{f}$ represent individuals and firms strategies respectively, and $b(e)$ represents the firms beliefs function i.e., the probability (derived using Bayes' rule) that an individual with education $e$ is of high ability:

$$
\begin{aligned}
& a_{i}=\left\{\text { Choose } \quad e=e^{p} \quad \forall \theta\right. \\
& a_{f}=\left\{\begin{array}{l}
w=w^{p} \quad \text { if } e=e^{p} \\
w=y(e, 0) \quad \text { if } e \neq e^{p}
\end{array}\right. \\
& b(e)= \begin{cases}0 & \text { if } e \neq e_{p} \\
\gamma & \text { if } e=e_{p} .\end{cases}
\end{aligned}
$$

It is easy to see that profile $a^{p}=\left[a_{i}, a_{f}, b(e)\right]$ is a pooling $P B E$. In the figure, given the wage schedule, both type of workers are better off by choosing $e^{p}$ earning a wage equal to $w^{p}$ (point $A$ ). At the same time, it is possible to show that the beliefs function $b(e)$ in (7) is not consistent with forward induction or reasonable beliefs. Consider all the education levels between $e^{\prime \prime}$ and $e^{\prime}$ in Fig. 1. If firms observe an individual with a level of schooling within this interval, a forward reasoning must lead to the conclusion that:

$$
b(e)=1 \forall e \in\left(e^{\prime \prime}, e^{\prime}\right) .
$$

In fact, only the high ability type can be better off by choosing $e \in\left(e^{\prime \prime}, e^{\prime}\right)$ with respect to point $A$. The low ability type strictly prefers to locate in point $B$ since by acquiring $e \in\left(e^{\prime \prime}, e^{\prime}\right)$ he would be worse off even if he were paid a wage equal to the high ability workers' productivity. This consideration implies that if firms observe $e \in\left(e^{\prime \prime}, e^{\prime}\right)$

\footnotetext{
${ }^{5}$ In signaling settings, game theorists refer to relation (3) as the single crossing property.
}

they must set their beliefs consistently with the (8) that is, a worker with this education must be an high ability type. As a consequence, as far as the cost functions are different for individuals with different ability, the only equilibrium consistent with reasonable beliefs or forward induction must be a separating equilibrium where, low ability individuals locate in point $B$ and high ability individuals locate in point $C{ }^{6}$

\section{THE ModeL}

Consider an infinitely repeated version of the interaction process similar to the one described above, but assume that the cost of acquiring education $c(\cdot)$ is also a function of the quality of education $q$. We assume that the quality of education is determined by the governmental policy implemented in period $s$ (with $s=1,2, \ldots \infty$ ) and it is distributed with a uniform density function on the support $\left[0, q^{\max }\right]$. We assume that the single cross property (3) holds only if $q>\bar{q}$ where $\bar{q}$ indicates the average value of $q$. Without loss of generality we can normalize $q^{\max }=1$ such that $q \sim U[0,1]$ and $\bar{q}=\frac{1}{2}$. Hence, in period $s$ :

$$
c_{e}\left(e, \theta_{l}, q\right)>c_{e}\left(e, \theta_{h}, q\right) \quad \text { iff } \quad q_{s}>\frac{1}{2} .
$$

Relation (9) implies that if the quality of education is set no higher than its average level $\left(q \leq \frac{1}{2}\right)$ the single crossing property disappears and the marginal cost of education is identical for individuals with different ability. We assume also that:

$$
c_{e q}\left(e, \theta_{l}, q\right)>c_{e q}\left(e, \theta_{h}, q\right) \text { iff } q_{s}>\frac{1}{2}
$$

where $c_{e q}(\cdot)$ is the cross partial derivative of the cost function with respect to the level and the quality of education. The implication of equation (10) is that a reduction in the quality of education lowers the indifference curves of low ability more than those of high ability individuals. The net effect of a decrease in $q$, illustrated in Fig. 2, results in the fact that the indifference curves of low and high ability individuals become less distant from each other and, when $q \leq \frac{1}{2}$ the two maps become as one. ${ }^{7}$ We assume that the quality of education, and hence the cost of acquiring it, is observed only by individuals.

In particular, we assume that firms do not observe the education cost function in period $s\left(c_{s}(\cdot)\right)$, but they observe only its past values (up to $s-1$ ). In period $s$ firms need to formulate expectations on $q_{s}$ in order to deduce $c_{s}(\cdot)$.

The interaction process that takes place in each period $s$ is described in Fig. 3. In particular, each period $s$ consists of $t=0,1,2,3$ instants of time. Using the Harsanyi (1968/69) approach, at time $t=0$ Nature chooses all the elements that are not common knowledge. In our case Nature chooses

\footnotetext{
${ }^{6}$ In order to simplify the illustration, we are assuming that the indifference between $B$ and $C$ is resolved in favor of $B$; alternatively we could increase $e^{\prime \prime}$ by an arbitrarily small amount so that the $\theta_{l}$ individuals would strictly prefer to locate in point $B$.

${ }^{7}$ See Ordine and Rose $(2007 \mathrm{a}, \mathrm{b})$ for other applications of changes in the quality of education on individuals' indifference curves.
} 


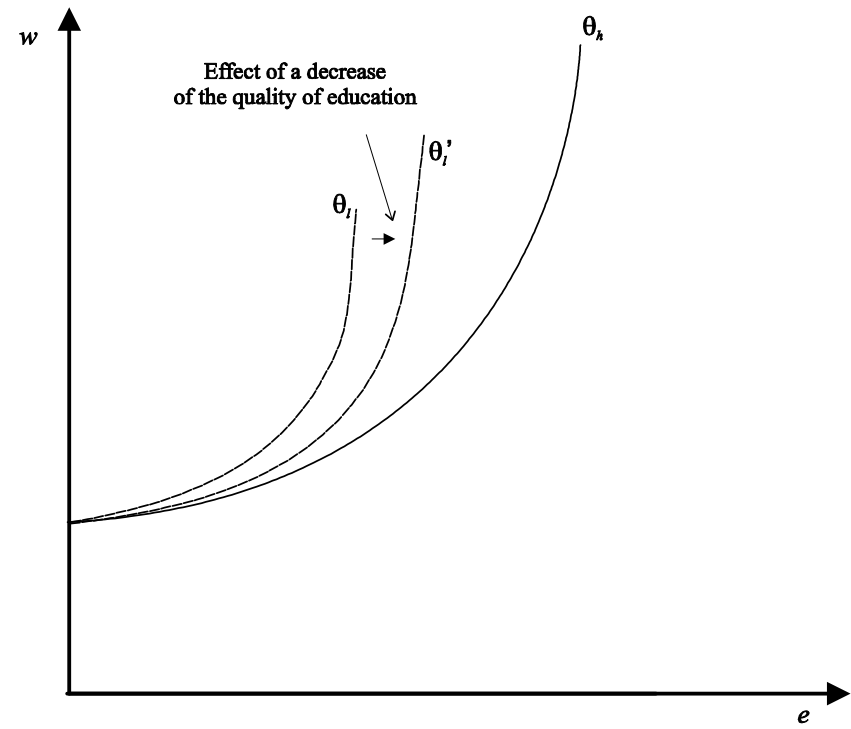

Fig. 2. Effects of a decrease in the quality of education

randomly the vector $\omega=\left[\theta_{a}, q_{s}\right]$. At time $t=1$ individual chooses the education level he wants to acquire contingent on his type and conditional on the observed quality of education. At time $t=2$, conditional on seeing a level of education $e$, firms make wage offers simultaneously. At time $t=3$ the individual decides which offer to accept, if any. Equilibria are analyzed for both the one-shot $(s=1)$ and the infinitely repeated version $(s \rightarrow \infty)$ of the game.

\section{THE EQUiLIBRIA}

The equilibrium concept used to solve the model is perfect Bayesian equilibrium consistent with forward induction (Kohlberg and Mertens, 1986). We define a $P B E$ as the profile of strategies and beliefs expressed by the assessment $a^{*}=\left[a_{i}^{*}\right.$, $\left.a_{f}^{*}, b(e)\right]$.

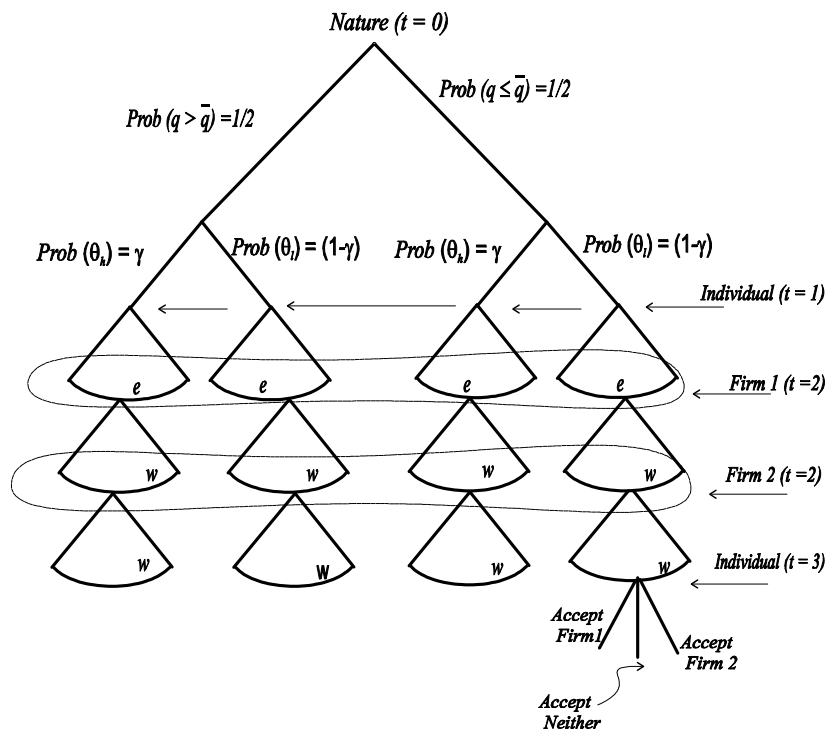

Fig. 3. The extensive form of the new job market signaling game
In the $P B E$ concept, the elements which are not common knowledge are (Bayesian) updated by players. In our case, since the element that should allow to obtain the signal on individual's ability (the cost of acquiring education) is not common knowledge, firms need to formulate expectation on it. As a consequence, firms' beliefs on $e$ are conditional to firms' expectation on $q_{s}$. In particular the beliefs function is:

$$
b(e)=b\left(e \mid E\left[q_{s} \mid s-1, \sim U\right]\right) .
$$

Equation (11) assumes that firms formulate rational expectation on $q_{s}$, which implies that firms use all the informations they have in period $s$ in order to estimate $q_{s}$. This information set is given by $(s-1)$ which represents all the realizations of $q$ till $s-1$ and it is also given by $(\sim U)$ which represents the prior knowledge concerning the distribution of $q$.

\section{A. The Equilibria in the One-Shot Game}

Proposition 1: If $q \leq \frac{1}{2}$ the only PBE of the game described in Fig. 3 is a (degenerated) pooling equilibrium.

Proposition 2: If $q>\frac{1}{2}$ any PBE of the game described in Fig. 3 consistent with forward induction must be a pooling equilibrium.

The proofs of Proposition 1 and Proposition 2 are given in the Appendix. The intuitions behind these are straightforward. Since $s=1$,

$$
E[q \mid s-1, \sim U]=\frac{1}{2}
$$

and this does not allow for education to be a signal of individuals' ability. Firms will offer a wage that reflects the average productivity $y^{m}$. If the actual realization of $q$ is $q \leq \frac{1}{2}$ the outcome is trivial since no signal can be sent and individuals acquire the same level of education independently on their ability. If $q>\frac{1}{2}$ the indifference curves are actually different for the two types of individual. But here, the beliefs function $b(e)=\gamma$ (for all $e$ ) is consistent with forward induction since whatever is the level of education observed by firms, they may think that they are just making a mistake in estimating the individuals cost functions. The best thing that firms can do is to estimate the two maps of indifferent curves as one and this generates only pooling equilibria.

\section{B. The Equilibria in the Infinitely Repeated Version of the Game}

Proposition 3: If the quality of education has not been intensely modified during its history and it has been always set in order to generate the single cross property, the only equilibrium consistent with forward induction is a separating equilibrium.

Proposition 4: If the quality of education has been intensely modified during its history, even if it has been always set in order to generate the single cross property, the only equilibrium consistent with forward induction is a pooling equilibrium.

The proofs of Proposition 3 and Proposition 4 are given in the Appendix. Here we present the main intuitions of the results. 
By assuming rational expectations, firms use all the informations they have in period $s$ to estimate $c_{s}(\cdot)$ :

$$
E\left[q_{s} \mid s\right]
$$

where $s$ indicates firms' information set in period $s$. Once the education cost is realized, it may differ from the firms' expectation only for a random error:

$$
c_{s}=E\left[c_{s} \mid s\right]+\epsilon_{s}
$$

where $\epsilon_{s}$ is a white noise, with zero mean and variance $\sigma_{\epsilon}^{2}$, with:

$$
\operatorname{Cov}\left(E\left[c_{s} \mid s\right], \epsilon_{s}\right)=0
$$

by hypothesis of rational expectations.

Consider Fig. 4 and consider the following assessment $a^{*}=$ $\left[a_{f}^{*}, a_{i}^{*}, b(e)\right]$ which represents a pooling $P B E$ of the game:

$$
\begin{gathered}
a_{i}^{*} \Rightarrow\left\{\text { Choose } e=e^{p} \forall \theta\right. \\
a_{f}^{*} \Rightarrow \text { set } w=\left\{\begin{array}{lll}
y^{m} & \text { if } & e \geq e^{p} \\
y(e, 0) & \text { if } & e<e^{p}
\end{array}\right. \\
b(e)=\left\{\begin{array}{lll}
\gamma & \text { if } & e \geq e^{p} \\
0 & \text { if } & e<e^{p} .
\end{array}\right.
\end{gathered}
$$

In the figure, differently from what we argued in Section 2 , in the presence of policies reducing the marginal cost of education, the above pooling equilibrium is consistent with forward induction. In fact, a level of schooling $e \in\left(e^{\prime \prime}, e^{\prime}\right)$ does not necessary imply that individuals with such education must be high ability types. As an example, to set $b\left(e^{\circ}\right)=\gamma$ can be consistent with forward induction since firms know that they can make an error $\epsilon_{s}$ in evaluating $c_{s}(\cdot)$. If firms observe an individual with education $e \in\left(e^{\prime \prime}, e^{\prime}\right)$ they can consider him as a low ability type in the presence of policies that lower the education quality. This last sentence expresses a reasoning whose consistency with forward induction strictly depends on the variance of $\epsilon_{s}$. In the presence of low variance of the quality of education $\left(\sigma_{\epsilon}^{2} \rightarrow 0\right)$ the beliefs function (18) would be not consistent with a forward reasoning and, as a consequence, only separating equilibria may arise (Proposition 3 ). On the other side, when the variance of the error $\epsilon_{s}$ diverges because of the intense use of policies on education, beliefs in (18) are reasonable for all $e \in\left(e^{\prime \prime}, e^{\prime}\right)$ even if the cost of education has been always different for individuals with different ability (Proposition 4). In other words, the intensity in the effective use of policies on education $\left(\sigma_{\epsilon}^{2}\right)$ determines the "reasonability" of beliefs in (18). ${ }^{8}$

\footnotetext{
${ }^{8}$ In this example we considered still a Bertrand competition between firms. Note that mutatis mutandis the same results discussed here hold if firms decide
} to collude and lower the wage curves.

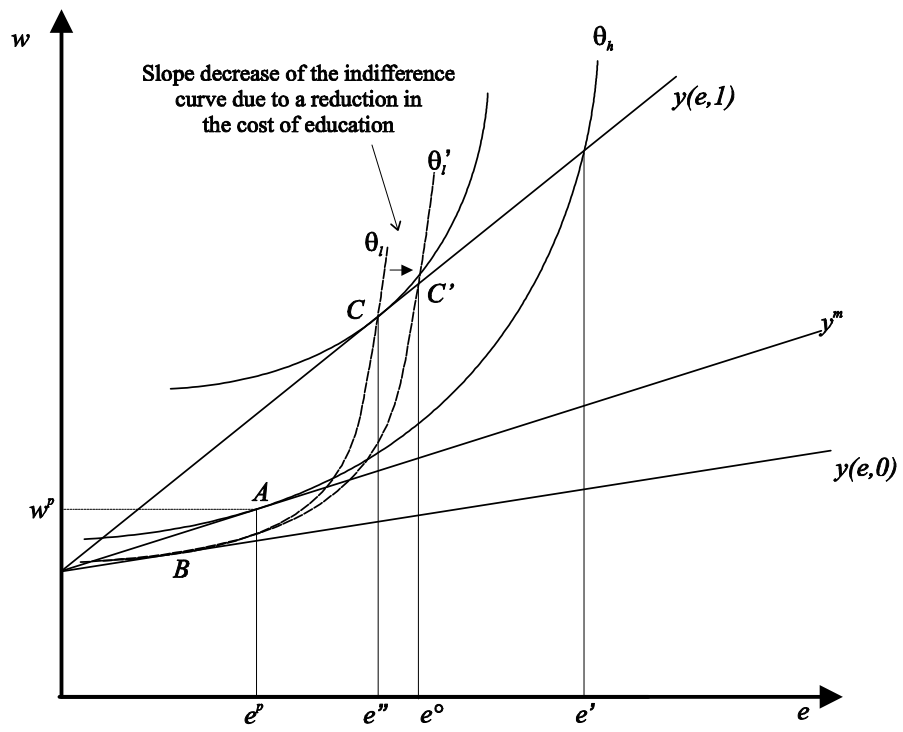

Fig. 4. Effects on reasonable beliefs of a reduction in the marginal cost of education

\section{Policy IMPLICATION}

Discussions on problems in higher education in Europe typically focus on rising enrolment rates, access, governance, underperformance on research and teaching, lack of internationalism, lack of funding. Many authors (among others see van der Ploeg and Veugelers, 2006; Jacobs and van der Ploeg, 2005) propose deep reforms in order to achieve more autonomy for universities, higher tuition fees, more private funding, more competition and internationalization. At the same time, these authors suggest that in order to leave higher education diverse across the EU with respect to languages, culture, systems and traditions, competence in higher education must be kept mostly decentralized. In this paper we show that there may exist theoretical reasons for not leaving such reforms only to single member States since to shift competence to the EU level can indeed improve welfare. In the presence of continuous (and, as in the Italian case, contradictory) reforms implemented without a long run perspective a side effect may arise confusing the value that firms associate to a particular degree. Firms would not be able to associate a "value" in terms of ability to each educational degree level. In this context, less Pareto efficient pooling equilibria may arise. In the light of the importance that talent has to firms, we suggest that in order to implement the necessary reforms for higher education, the role of European Union should be central. We suggest that European Union should not only take a subsidiary perspective by supporting the building of higher education infrastructure through Structural Funds. The role that European' directives may have in addressing long run reforms can be fundamental in order to modernize the higher education system and to avoid the effects of reforms biased by political conveniences.

\section{CONClusions}

In this paper we argue that, if policies that affect the educational system are not based on a long run perspective, but rather these make only continuous endeavours of 
modernization that affect the education quality, the whole economy may be lead to (Pareto) inefficient equilibria. In particular, using a strategic interaction framework we show that in the job market signaling game, the continuous use of policies that affect the quality of the educational system can re-establish pooling equilibria consistently with a forward induction reasoning. This happens since in the presence of an intense use of policies, education may loose its signal value. In the last fifteen years many works focused their attention on higher education sectors in Europe. Many of these studies point out that European universities would benefit from reform in the direction of the Anglo-Saxon system of higher education that is characterized by much more choice, differentiation and competition. The general principles that Member States should follow in order to implement such reforms have been indicated in the Bologna agreement and they are continuously updated by the works of the European Commission and of the Council of the European Union. At the same time, it is important to consider that only Member States (and not the EU) can implement the necessary restructuring and modernization. We suggest that, while there exist some theoretical and empirical justifications to reform the higher education sector, governments should use only policies based on a long run perspective. Policy measures that deeply affect the educational system should be based on the indications given by special commissions targeted to identify the main issues and to give informed answers to them. In this sense, the role that European Union' directives may have in addressing long run reforms can be fundamental in order to modernize the higher education system.

\section{APPENDIX}

Proof of Proposition 1 Since the single crossing property (3) does not hold and firms' beliefs are updated considering that there is no single crossing property, the game is degenerated in a game where everything is common knowledge. Hence, individuals maximize their utility at the same level of education and we have only a (degenerated) pooling equilibrium.

Q.E.D.

Proof of Proposition 2 We show that if $q>\frac{1}{2}$ and $E[q \mid \sim U] \leq \frac{1}{2}$, no separating equilibrium may exist. By contradiction, consider Fig. 1 and consider the following assessment $a^{*}=\left[a_{f}^{*}, a_{i}^{*}, b(e)\right]$ (where $\xi$ is a small positive number) which represents a separating $P B E$ of the game described in Fig. 3:

$$
\begin{aligned}
& a_{i}^{*} \Rightarrow \begin{cases}\text { Choose } e=e^{\prime \prime}+\xi & \text { iff } \theta=\theta^{h} \\
\text { Choose } e=e^{b} & \text { iff } \theta=\theta^{l}\end{cases} \\
& a_{f}^{*} \Rightarrow \text { set } w=\left\{\begin{array}{lll}
y(e, 1) & \text { if } \quad e>e^{\prime \prime} \\
y(e, 0) & \text { if } \quad e \leq e^{\prime \prime}
\end{array}\right. \\
& b(e)=\left\{\begin{array}{ccc}
1 & \text { iff } & e>e^{\prime \prime} \\
0 & \text { iff } & e \leq e^{\prime \prime} .
\end{array}\right.
\end{aligned}
$$

Since $E[q \mid \sim U] \leq \frac{1}{2}$, firms know that all the educational levels $e$ such that $e^{\prime \prime}<e<e^{\prime}$ can be acquired by both high and low ability individuals because $b(e \mid E[q \mid \sim U])=\gamma$. As a consequence, in Fig. 1, setting $b(e)=1$ for $e>e^{\prime \prime}$ does not express a reasonable belief, and we have a contradiction. The same argument can be replicated for all the possible separating equilibria.

Q.E.D.

Proof of Proposition 3 and 4 Consider firms' rational expectations $E\left[q_{s} \mid s-1, \sim U\right]$. Since

$$
q_{s}=E\left[q_{s} \mid \sim U\right]+u
$$

where $u \sim \mathcal{N}\left(0, \sigma_{u}^{2}\right)$ with $\sigma_{u}^{2}=\frac{1}{12}$; and

$$
q_{s}=E\left[q_{s} \mid s-1\right]+\varepsilon_{s}
$$

where $\varepsilon_{s} \sim \mathcal{N}\left(0, \sigma_{\varepsilon}^{2}\right)$, indicating with

$$
b=q_{s}-E\left[q_{s} \mid \sim U\right]
$$

where

$$
E[b \mid \sim U]=0
$$

we have that:

$$
b+E\left[q_{s} \mid \sim U\right]=E\left[q_{s} \mid s-1\right]+\varepsilon_{s}
$$

which can be rewritten as:

$$
E\left[q_{s} \mid s-1\right]-E\left[q_{s} \mid \sim U\right]=b-\varepsilon_{s} .
$$

Taking expectation of both sides in (27) conditional to $(\sim$ $U)$ leads to:

$$
\begin{aligned}
E\left[q_{s} \mid s-1,\right. & \sim U]= \\
E\left[q_{s} \mid\right. & \sim U]+E\left[b-\varepsilon_{s} \mid \sim U\right]
\end{aligned}
$$

or, using (27), equivalently:

$$
\begin{aligned}
E\left[q_{s} \mid s-1, \sim\right. & U]= \\
& E\left[q_{s} \mid s-1\right]-(b-\varepsilon)+E\left[b-\varepsilon_{s} \mid \sim U\right]
\end{aligned}
$$

Since

$$
E\left[q_{s} \mid s-1\right]-E\left[q_{s} \mid \sim U\right]=u-\varepsilon_{s}
$$

equation (27) can be written as:

$$
u-\varepsilon_{s}=b-\varepsilon_{s}
$$

taking expectation of both sides conditional on $b-\varepsilon_{s}$ leads to:

$$
E\left[u-\varepsilon_{s} \mid b-\varepsilon_{s}\right]=b-\varepsilon_{s} .
$$

Substituting this last result in equation (29) yields to:

$$
\begin{aligned}
E\left[q_{s} \mid s-1, \sim\right. & U]= \\
& E\left[q_{s} \mid s-1\right]-E\left[u-\varepsilon_{s} \mid b-\varepsilon_{s}\right]
\end{aligned}
$$

since

$$
E\left[b-\varepsilon_{s} \mid \sim U\right]=0 .
$$


Rewriting (33) as:

$$
\begin{aligned}
E\left[q_{s} \mid s-1, \sim\right. & U]= \\
& E\left[q_{s} \mid s-1\right] \\
& -\frac{\operatorname{cov}\left(u-\varepsilon_{s}, b-\varepsilon_{s}\right)}{\operatorname{var}\left(b-\varepsilon_{s}\right)} E\left[b-\varepsilon_{s}\right]
\end{aligned}
$$

and using (27) lead to:

$$
\begin{aligned}
& E\left[q_{s} \mid s-1, \sim\right.U]= \\
& E\left[q_{s} \mid s-1\right] \\
&-\frac{\operatorname{cov}\left(u-\varepsilon_{s}, b-\varepsilon_{s}\right)}{\operatorname{var}\left(b-\varepsilon_{s}\right)}\left(E\left[q_{s} \mid s-1\right]\right. \\
&\left.-E\left[q_{s} \mid \sim U\right]\right) .
\end{aligned}
$$

Assuming that:

$$
\begin{aligned}
\operatorname{cov}\left(u, \varepsilon_{s}\right) & =0 \\
\operatorname{cov}\left(b, \varepsilon_{s}\right) & =0 \\
\operatorname{cov}(u, b) & =0
\end{aligned}
$$

it is possible to write equation (36) as:

$$
\begin{aligned}
E\left[q_{s} \mid s-1, \sim\right. & U]= \\
& E\left[q_{s} \mid s-1\right] \\
& -\frac{\sigma_{\varepsilon}^{2}}{\sigma_{\varepsilon}^{2}+\sigma_{u}^{2}}\left(E\left[q_{s} \mid s-1\right]-E\left[q_{s} \mid \sim U\right]\right)
\end{aligned}
$$

or equivalently:

$$
\begin{aligned}
& E\left[q_{s} \mid s-1, \sim U\right]= \\
& \frac{\sigma_{u}^{2}}{\sigma_{\varepsilon}^{2}+\sigma_{u}^{2}} E\left[q_{s} \mid s-1\right] \\
& \quad+\frac{\sigma_{\varepsilon}^{2}}{\sigma_{\varepsilon}^{2}+\sigma_{u}^{2}} E\left[q_{s} \mid \sim U\right] .
\end{aligned}
$$

Equation (41) indicates how firms weight the information they have in order to estimate the quality of education to generate their beliefs function. It is important to note that:

- As $\sigma_{\varepsilon}^{2} \rightarrow 0$ the firms expectation on $q$ will be based only on its past observation, hence if $E\left[q_{s} \mid s-1\right]>\frac{1}{2}$ a separating equilibrium arise. (Proposition 3, Q.E.D.)

- As $\sigma_{\varepsilon}^{2} \rightarrow \infty$, even if in the past education has been acquired always with an higher cost for the low ability individuals, i.e. $E\left[q_{s} \mid s-1\right]>\frac{1}{2}$, because of the perturbation generated by the intense use of policies, the expectation on $q$ are set at a level $\left(E\left[q_{s} \mid \sim U\right]\right)$ that, given Proposition 2, does not induce firms to consider education as a signal. (Proposition 4, Q.E.D.).

\section{ACKNOWLEDGMENT}

I would like to thank Patrizia Ordine and Sandeep Kapur for their useful comments.

\section{REFERENCES}

[1] Cho, I-K, and Kreps, D., 1987 "Signaling Games and Stable Equilibria." Quarterly Journal of Economics, 102, 179-222.

[2] Council of the European Union, 2005 "Resolution of the Council and of the Representatives of the Governments of the Member State, meeting within the Council , on mobilising the brainpower of Europe: enabling higher education to make its full contribution to the Lisbon Strategy." Official Journal of the European Union 2005/c 291/01, vol. 48, 24 November 2005.

[3] European Commission 2005, "Mobilising the brainpower of Europe: enabling higher education to make its full contribution to the Lisbon Strategy". Communication from the Commission, $\operatorname{COM}(2005) 152$, SEC(2005) 518, 20 April 2005.

[4] Harsanyi, J.C., 1967/68 "Games with incomplete information played by Bayesian players." Management Science, 159-82, 320-34, 486-502.

[5] Jacobs, B., and van der Ploeg, F., 2005 "Guide to Reform of Higher Education: a European Perspective." Panel Meeting of Economic Policy, October, London.

[6] Kohlberg, E., and Mertens, J.F., 1986 "On the Strategic Stability of Equilibria." Econometrica, 50, 863-94.

[7] Lucas, R.E., 1976 "Econometric Policy Evaluation: A Critique." Carnegie-Rochester Conference Series on Public Policy, 1, 19-46.

[8] Mas-Colell, A., Whinston, M.D., and Green, J.R., 1995 Microeconomic Theory. New York: Oxford University Press.

[9] Ordine, P., and Rose, G., 2007a "Students Mobility and Regional Disparities in Quality and Returns to Education in Italy." Giornale degli Economisti ed Annali di Economia, 66, 149-176.

[10] Ordine, P., and Rose, G., 2007b "The Supply of Education Quality in a Spatial Model with Asymmetric Moving Costs." Research in Economics, vol. $62,192-214$

[11] Rodriguez, R., 2000 "Higher Education Reform: Signs From the end of the Century International Debate." Revista Electronica de Investigacion Educativa, 2, 1-17.

[12] Spence, A.M., 1973 "Job Market Signaling." Quarterly Journal of Economics, 87, 355-74.

[13] Spence, A.M., 1974 "Competitive and Optimal Responses to Signaling: An Analysis of Efficiency and Distribution." Journal of Economic Theory, 8, 296-332.

[14] Spence, A.M., 2002 "Signaling in Retrospect and the Informational Structure of the Market", American Economic Review, 92, 434-459.

[15] van der Ploeg, F., Veugelers, R., 2006 "Higher Education Reform and the Renewed Lisbon Strategy: Role of Member States and the European Commission." To appear in Economic Reform in Europe, Gelauff, G., Grilo, I., and Lejour, A. (Eds.), Kluwer: Dordrecht. 